origin of species, the genesis of the colours of flowers, the laws of variation, and other similar subjects. Dr. Müller's contribution, "Blumen und Insekten," to Schenk's "Handbuch der Botanik," which forms a part of the "Encyklopædie der Naturwissenschaften," now in course of publication, is an admirable résumé of the whole subject.

Dr. Müller died in harness, having fallen a victim to an attack of inflammation of the lungs at Prad, in Tyrol, on August 25.

A. W. B.

\section{SECOND NOTE ON THE ELECTRICAL RESISTANCE OF THE HUMAN BODY}

THE fact that the note on this subject inserted in NATURE, June 14, p. I5 I, was copied in extenso by the Electrical Reviere, by the New York Electrical World, and I believe by some other papers, as well as the fragmentary way in which these observations must of necessity be obtained, encourages me to ask for a little further space. This is the more pardonable as the writer in the former paper, in two editorial articles which he founds on my observations, shows ignorance and misconception of certain physiological facts involved in them - a misconception the correction of which by myself he does not think fit to publish.

On August 23, during my visit to the ward, it became obvious that a hopeless and incurable case of renal disease was rapidly sinking. It occurred to me that the patient, being in a state of uræmic drowsiness almost amounting to coma, there would be no inhumanity in adding small electrical currents to the other stimulants which as a last chance we were sedulously administering. I accordingly immersed his feet, which were rapidly getting cold, in hot baths of salt and water connected with Wheatstone's bridge. This and the brandy caused a decided rally, and the temperature became normal, viz. $98^{\circ} \mathrm{F}$. The resistance then taken was 1100 ohms from one foot to the other. At 3 p.m., however, he rather suddenly relapsed, his hands and nose becoming cold. The following series of observations was taken :-

$$
\begin{aligned}
& 2.55 \text { p.m. - temperature } 98^{\circ} \quad \ldots \quad \ldots \quad \text { r IoO }
\end{aligned}
$$

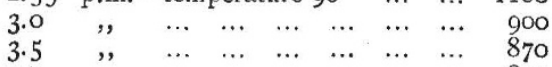

$$
\begin{aligned}
& \begin{array}{lllllllll}
3.5 & , & \ldots & \ldots & \ldots & \ldots & \ldots & \ldots & 870 \\
3.7 & , & \ldots & \ldots & \ldots & \ldots & \ldots & \ldots & 850
\end{array} \\
& \begin{array}{lllllllll}
3.1 & , & \ldots & \ldots & \ldots & \ldots & \ldots & \ldots & 850 \\
3.12 & , & \ldots & \ldots & \ldots & \ldots & \ldots & \ldots & 840
\end{array} \\
& \begin{array}{lllllllll}
3.13 & , & \ldots & \ldots & \ldots & \ldots & \ldots & \ldots & 840
\end{array}
\end{aligned}
$$

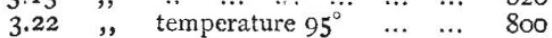

We concluded that death was imminent, and I ceased the experiment, intending to renew it after the event. But on returning to the ward at 4.36 I found him somewhat better and warmer. I applied the large leaden poles, to which I will refer presently, to both feet, so as to reduce the resistance to. a minimum. The following remarkable series of resistances was obtained. The thermometer, ${ }^{1}$ being found too slow in its action to follow the flickerings of the expiring lamp of life, was not used, the hand applied to the skin being quite competent to detect the great changes of surface heat :-

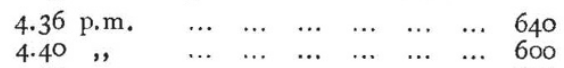

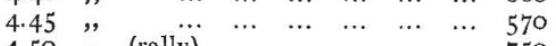

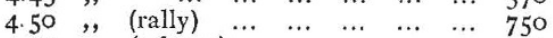

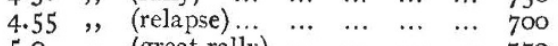

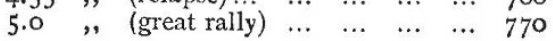

He was still very cold, but began to ramble in his usual incoherent way (having been slightly deranged for several years), and I therefore left him for the night. On returning next morning early I found he had died an hour and a half later. Had I not been greatly fatigued myself, I should have stopped to secure an observation during post-mortem refrigeration, and before the access of rigor

${ }^{x}$ In the axilla. I hope to use surface thermometers on a future occasion. In my former paper the axillary temperature obviously lags behind that of the extremities. mortis. As it was I found the corpse in full state of rigidity. We managed to have the testing apparatus set up by I2.30, and without any great disturbance of the body I applied the leaden poles.

After some preliminary tests I obtained two excellent observations with reversed currents, and found them both exactly alike at 1150 ohms.

Then came the last experiment with which I now have to trouble you, namely, the question of skin resistance. A tremendous hubbub has been made about this since the time of Duchenne. I believe it has been enormously exaggerated. My anonymous critic of the Electrical Review quaintly says: "We most of us" (sic) "know the effect of keeping the feet in sait and water, or water alone" (he does not name soap and water!) "for any length of time. The skin turns white and swells, enlarging the pores (sic); indeed nearly the whole of the outside skin is of a spongy nature." I need not prolong the quotation, because I simply deny his facts, except where foot-washings have been "like angels' visits," \&c., \&c. The carefully-prepared epidermis of my patients is entirely free from this hypothetical and inaccurately stated cause of error. So I hope is mine ; indeed I feel the full value of the implied limitation of the cautious phrase "most of us." Seriously speaking, it is too bad that an observer of average capacity, and I hope moderate honesty, should be accused of such elementary blunders on mere a priori grounds. Now for fact : Before going to the deadhouse I had provided myself with two silver needles, used for the electro-puncture of aneurisms, and intended to convey a very strong coagulating current from a powerful battery. I inserted one of these to the depth of three inches into the plantar muscles of each foot of the corpse, leaving everything else untouched. I expected the enormous reduction of resistance above named. To my surprise the Wheatstone bridge gave $1200 \mathrm{ohms}$ in either direction of current, or 50 more than with large lead and salt-water electrodes. This alleged skin resistance is then only true in the dry state, and is easily conquered by very simple means. Cases of diabetes have been cited in confirmation of this supposed resistance, and it has been explained by the peculiar dryness of the skin in this complaint. A patient now in my ward, though a tall emaciated man with long spindle shanks, only gives $1340 \mathrm{ohms}$ from foot to foot, with either saltwater baths, or with the lead electrodes as here described. This is rather under than over the average.

One word as to the lead electrodes themselves, and the manner of using them. The intelligent and kind lady nurses of our hospital, whom I like to call by their grand old name of " sisters," and who throughout this inquiry have seconded me in the most self-sacrificing way, are instructed to get ready certain patients for me each morning. The process consists in wrapping both hands and feet in coarse flannel saturated with strong warm brine for an hour before the experiment. Sometimes the process so graphically described by my commentator occurs, and is dealt with accordingly. I then proceed to wrap the members one by one in a surgical covering of flannel soaked in the same conducting solution. Over this I fold, also in surgical fashion, a strip of thin sheet lead about eighteen inches long, and one and a half inches broad. On the top of all is an ordinary spiral bandage, which moulds the whole to the shape of the limb, and squeezes out superfluous fluid. An indiarubber covered wire leads to my testing table. I may add that each hand or foot is separately deposited on one of the vulcanised rubber waterproof sheets commonly used in the wards, and which I find to be excellent insulators. The first few observations are commonly rejected; always if they show any suspicion of diminishing. But after even half an hour's maceration this is rarely the case. Between every two observations I put the patient himself on short circuit, to discharge any currents of polarisation 
Every measurement is at least double, and made with currents in opposite directions.

In conclusion I may remark first, that this, like my former note, only deals with part of a larger inquiry ; and secondly, that the results above stated were open to all comers, and were carefully watched by Dr. Percy Smith, Dr. Shepherd, and others of my colleagues and pupils.

W. H. STONE

\section{THE INTERNATIONAL BUREAU OF WEIGHTS AND MEASURES ${ }^{1}$}

$A S$ the result of an International Convention held on A the 2oth May, 1875, an International Bureau of Weights and Measures has been created at Paris with the object of securing an international metric system, and which should take account ( 1 ) of all comparisons and verifications of the new prototypes of the metre and the kilogramme ; (2) of the conservation of the international prototypes; (3) of periodical comparisons of national standards with the international prototypes, as also of comparisons of thermometric standards ; $(4)$ of the comparisons of the new prototypes with the fundamental standards of non-metric weights and measures employed in different countries and in science; $(5)$ of the marking and comparison of geodetical measures; (6) of the comparison of standards and scales of precision, the verification of which may be sought by governments, by learned societies, or even by mechanists and students.

An international committee of weights and measures composed of fourteen members, comprising physicists, mathematicians, surveyors, and astronomers, all of different nationalities, has been intrusted with the supreme direction of the bureau. The president of this committee is General Ibañez, director-gencral of the Geographical and Statistical Institute of Spain, and its secretary Dr.

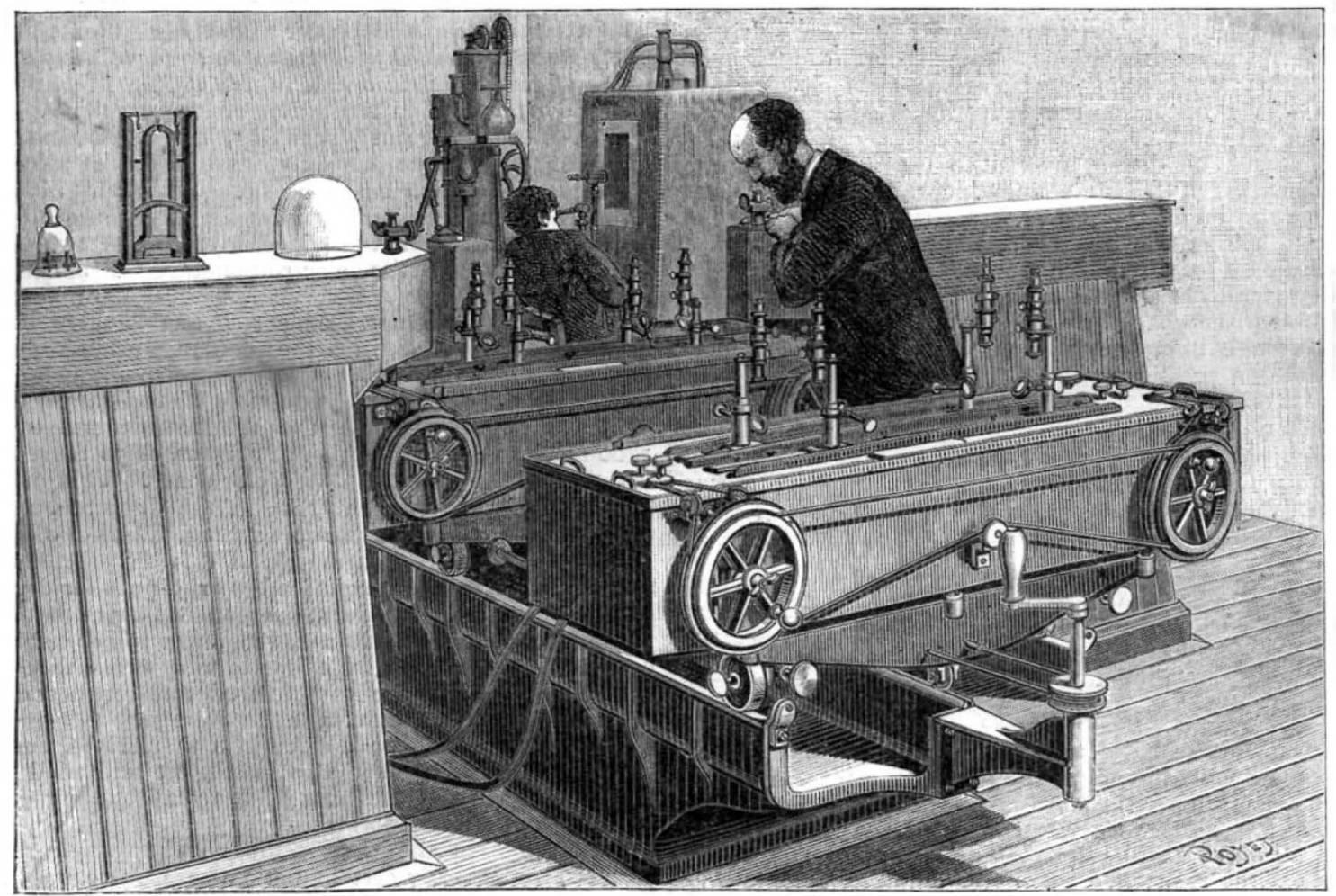

FIG. x.- "Comparateur " for Measuring Absolute and Relative Dilatations.

Hirsch, director of the Observatory of Neuchatel. It meets once a year for the discharge of its functions at Paris.

Twenty States were represented at the preliminary diplomatic conference of 1875. Of these, seventeen (or nineteen) have signed the international convention which was the result of its deliberations. One alone of these States has not ratified the convention; and consequently the expenses of the foundation and maintenance of the International Bureau of Weights and Measures have bicherto been defrayed by the following sixteen States Germany, Austria-Hungary, Belgium, the Argentine Confederation, Denmark, Spain, the United States of America, France, Italy, Peru, Portugal, Russia, Sweden, Norway, Switzerland, Turkey, Venezuela. These, representing about $35 \mathrm{I}, 000,000$ of people, have already contributed over $I, 000,000$ francs towards the foundation of I From La Nature. the International Bureau. The Government of Servia has since given in its adbesion to the convention.

In order to provide for the erection of the necessary structures for the observatory of the International Bureau of Weights and Measures, France made a grant of ground in the park of St. Cloud formerly occupied by the Pavillon de Breteuil, safely removed from all disturbances and surface tremors such as would have been experienced in the contre of a large city amidst the whirl of carriages and the working of machines.

In front of the observatory of the International Bureau are offices sct apart for mechanical laboratories. Behind are spacious chambers in which are distributed the various instruments of precision employed in metrological work. These chambers are surrounded by walls of great thickness; they are lighted by skylights so arranged as to prevent solar rays from penetrating: and are environed by a lobby i=olating them from the exterior. The object 